\title{
Aspects of Mobility in e-Marketing from the Perspective of a Customer
}

\author{
Witold Chmielarz \\ University of Warsaw, Faculty of Management, \\ in Warsaw \\ ul. Szturmowa 1/3, 02-678 Warsaw, Poland \\ Email: witold@chmielarz.eu
}

\author{
Marek Zborowski \\ University of Warsaw, Faculty of Management, \\ in Warsaw \\ ul. Szturmowa 1/3, 02-678 Warsaw, Poland \\ Email: mzborowski@wz.uw.edu.pl
}

\begin{abstract}
The main aim of this article is to analyze the use of marketing mechanisms on the Internet. To meet this objective, the authors conducted a study limited to a selected group of individual users - students of the University of Warsaw. The paper presents the characteristics of the application of marketing tools as well as the users' opinion on the usefulness of these tools in broadly defined e-commerce. The article also presents the discussion and the findings of the present study.
\end{abstract}

\section{INTRODUCTION}

$\mathbf{T}$ HE MAIN objective of this paper is to analyze the possibilities of using the Internet on mobile and desktop devices for marketing purposes, under the circumstances of the dynamic development of both mobile devices and mobile applications running on them. This article aims to examine the situation where basic marketing tools are used by clients on the desktop (PC) or portable equipment (e.g. a laptop) as well as the devices combining the advantages of a phone and a computer, i.e. smartphones and tablets.

There are numerous definitions of e-marketing presented by scholars and academics. They are as follows: electronic marketing may be defined as activities of an organization which through applying new technologies, in particular the Internet, uses the potential of the market (Meng X., 2009). Internet marketing is a combination of communication efforts undertaken by organizations, operating both in the physical and virtual markets, to satisfy individual and collective needs in the electronic space, with the application of information technologies, especially the Internet, in order to make a profit (Chmielarz, 2007). It encompasses among other things: the study of the behavior of Internet users, the development of new products as well as e-promotions, e-distribution and e-service. In addition, the definition of e-marketing may be extended to include also the approach which states that it comprises all marketing activities aimed at fulfilling the operational goals via the Internet. From a theoretical point of view, it is a result of a combination of modern marketing, management and risk management theories as well as the application of modern communication technologies (Sun, 2011; Hasan, 2011).

Mobile marketing may be defined as a part of electronic marketing, one of the methods of direct marketing, practiced via mobile devices such as e.g.: cell phones, smartphones, tablets, PDA, MDA and notebooks. In m-marketing the messages with commercial or non-commercial content are communicated with the application of such technologies as SMS, MMS, NFC and others (Hovancakowa, 2011; Bernauer, 2008). It includes also advertising activities taking advantage of mobile phones' functionalities (Wikipedia, 2016). The Mobile Marketing Association defines mobile marketing as any marketing, advertising or promotional activity, targeted at clients and transmitted using a mobile channel (Salo J., Sinisalo J., Karjaluto, 2008).

The phenomena of e-marketing and m-marketing have been examined in numerous studies (Åôwierczy ̊̊Ďska-Kaczor, 2012; Wielki, 2012; Kiba-Janiak M., 2014; Gao T., Sultan F., Rohm A. J., 2010; Roach G., 2009), including those carried out on a large scale (IAB, 2015; InternetStandard, 2015). Nevertheless, the majority of them took place before the most rapid development of smartphone and tablet applications or not takes into account this phenomenon. Fast, or rather rapidly growing, market of new mobile devices and the increasing pace of eliminating older devices from the market results in the fact that for the purpose of this article the authors have applied an additional division between traditional electronic marketing via the devices such as PC and laptop and a new mobile marketing, operated on smartphones and tablets. Unfortunately, in the present research the authors were not able to make a distinction between the traditional electronic marketing on the devices such as personal computers or laptops and mobile marketing used via these devices in browsers (browser marketing) and mobile marketing employed in applications (appbased marketing), because respondents are not always even aware of the distinction. Nevertheless, it allowed evaluating both forms of marketing used on smartphones and tablets.

The authors of the article hoped to indicate certain basic implications concerning the new phenomena impacting the directions of development of mobile marketing. Thus, they undertook a study whose main aim was to analyze the use of emarketing and $\mathrm{m}$-marketing among the users of different kinds of computer devices providing Internet access. The findings presented in the article constitute a summary report of the research examining a selected group of users in Poland at the beginning of 2016 . 


\section{RESEARCH METHODOLOGY}

Due to few and fragmentary studies concerning the sphere of e-marketing and m-marketing applications as perceived by an individual client in national and foreign literature, the present research was based on the authors' own approach [Chmielarz, 2015) consisting of the following stages:

- analysis of a selected group of users on the basis of a quantitative and qualitative survey (CAWI (Computer Associated Web Interview method)),

- making an online version of a questionnaire available on the servers of the Faculty of Management at the University of Warsaw, and subsequent testing and verifying it,

- conducting user surveys,

- analysis and discussion of findings,

- drawing conclusions from the obtained findings on the current state of e-marketing and m-marketing and future directions of their development, based on the opinions of users.

The detailed scope of the survey, which consists of twentyfive questions, divided into five sections, is presented below:

- the place and role of the Internet in marketing,

- the assessment of e-marketing as a source of information about products/services,

- the assessment of the effectiveness of e-marketing media and their acceptance by the client,

- the assessment of the utility of e-marketing from the point of view of a client,

- assessment of m-marketing.

The article presents the findings of the analysis of completed questionnaires. The survey was carried out in March-April in 2016. The selection of the group was not quite random; it was the case of convenience sampling: the respondents were students of part-time and full-time BA and MA studies at the University of Warsaw. The choice of students groups were random. The surveys were distributed electronically, the level of responsiveness slightly exceeded $80 \%$, despite the fact that students constitute a group which is particularly open to all kinds of innovations, especially those related to mobile devices. This group in Poland is the most active buyers in Internet.

A limitation in this sort of selection was an expected high participation of people owning smartphones, tablets, laptops and cell phones - not necessarily of high quality, but with a high usage time. The survey was completed by 130 people, with 106 respondents ( $81.54 \%$ of the sample) who completed the questionnaire correctly in its full form. Among the respondents, there were $65.09 \%$ women and $34.91 \%$ men. An average age of the respondent was 23.08 years, and the median value was 19 years of age. It is the typical age for the students of first years of part-time and full-time BA studies and the first years of MA studies, the interviewees who were asked to fill in the questionnaire. The oldest of the respondents was 51. Among the respondents, there were $65.09 \%$ of only students, $32.08 \%$ of working students and $23.89 \%$ professionals. Respectively, $66.98 \%$ declared having secondary education, and $27.36 \%$ of the respondents completed BA studies. Higher education and post-graduate studies were indicated by only $5.66 \%$ of the interviewees. Almost $36 \%$ of the respondents stated that they reside in cities of more than 500,000 inhabitants, over $12 \%$ came from cities of 100-500,000 inhabitants, more than $11 \%$ from cities with $50-100,000$ residents, almost $21 \%$ of the sample were from towns with 50,000 inhabitants, and $19.81 \%$ from rural areas. The simplicity of the survey did not cause many distortions in the process of its completion.

\section{DATA ANALYSIS AND DISCUSSION OF FINDINGS}

Respondents provided answers to twenty-five substantive questions. Here we concentrate on aspect of m-marketing in the frames of e-marketing, but survey had more wide context. The most important findings are listed below.

The first group of questions concerned generally the place and role of the Internet in marketing. Over $95 \%$ of respondents said that they use the Internet several times a day, $3.77 \%$ at least once a day, and only one respondent stated that he/she seldom uses the Internet.

The most popular device used by the respondents when accessing the Internet is a smartphone (33\%), or a smartphone interchangeably with the laptop (32\%). The laptop is used by slightly over $11 \%$ of students. Almost $8.5 \%$ of the survey participants use a personal computer for this purpose. This indicates a significant reorientation of Internet users towards the device which they have learned to use relatively early in life and use it for the longest time, that is, handheld mobile devices, especially a smartphone (the tablet itself is used by only by $3.77 \%$ of respondents).

Generally, the Internet is seen as a very good marketing medium by $52 \%$ of the respondents, or as a good marketing medium by $33 \%$ of the sample. Only $15 \%$ of the interviewees perceive the Internet as average or sufficient. Nobody has rated it as unsatisfactory. What lies at the core of such discrepancy between the level of using the Internet, making online purchases and a very good or good opinion on internet marketing? It appears that it stems not only from the specific shift of emphasis towards communication (as it is the main purpose of using smartphones) but also from the fact that the Internet has become the basic source of information on the reality, not only an economic one. The obtained information on products and services can also lead to making purchases in a traditional way, not only via websites. Also, one needs to consider the fact that the Internet, apart from its communication and information function plays a more and more important role as a means for providing entertainment (films, music, e-books, computer games, etc.). The last question in this section of the survey concerns the statement whether internet marketing is - in the opinion of the Internet users - better than traditional marketing. The majority of responses - i.e. 53\% claimed that the best option is a combination of traditional and internet marketing (marketing mix). Interestingly, almost $40 \%$ of responses show that internet marketing is better than traditional marketing, and only $7.5 \%$ of the responses point out that it is just the opposite. The first thing which comes to the fore is the question why 
internet marketing might be seen as better than its traditional form. The opinions concerning the reasons were divided. In almost $25 \%$ of responses of participants of the survey, they paid attention to its continuous accessibility and $23 \%$ to the possibility of gathering information about a particular product or service. The third place with the score of $22 \%$ was taken by the opportunity to use internet comparison engines, directly supporting the purchase process with special software. The fourth position was taken by the possibility of direct purchase after clicking on the link (19\%). It should be noted that the difference between the evenly distributed attributes, in total, amounts to only six percentage points. Information about products and services on the Internet are mainly collected through search engines (almost 49\% responses). Social media take the second position with the score of $28 \%$, which is nearly 20 percentage points higher than the source which is in the first position. The blog entries and links to banners were at the level of $10 \%$ of responses. At the same time in order to verify the importance of the above information, the authors examined the percentage of people who perceive the Internet as the main source of information. Actually, in the examined group of respondents the Internet undoubtedly gained considerable recognition as a source of knowledge about products and services - 33\% of responses. The next, second position was taken by information provided by friends (28\% - word-of-mouth advertising). As the survey shows, television still enjoys a strong position (16\% responses). The press and advertising materials in shops reached a similar level of about $8 \%$ of responses. However, the role of the radio and leaflets is markedly depreciated. The research also pointed to the low score of the opinions of the industry experts in the ranking.

Interestingly, information about the products and services is mainly used by the participants of the survey to make purchases in traditional stores (47\% of responses), which would confirm the thesis concerning the importance of the Internet with regard to its informative function. Nevertheless, an almost equally large group of users (42\% of responses) use the information to buy items in online shops and $10 \%$ on online auctions. This partly justifies the low percentage of Internet users declaring shopping in the electronic sphere - a considerable group use the information available on the Internet to make purchases in traditional stores.

The next section concerns the evaluation of the usage of e-marketing media and their acceptance by the client. For the Internauts, the presence in social media with the score of $30 \%$ of responses turned out to be the most significant factor. Nearly $22 \%$ of responses of students admitted that the most important factor inducing the purchase was an attractive website design. The least attention among the respondents assigning good scores was paid to e-mailing (nearly $5 \%$ of responses). In total, the presence in social media has obtained $46 \%$ of very good and good scores, and the clear and attractive website has gained $44 \%$, which is a slightly lower score. Consequently the greatest number of negative scores was obtained by emailing (more than 50\%) and a newsletter $23 \%$ of responses.
The fourth section of the survey concerns the evaluation of the usage and the success of e-marketing from the point of view of a client. The ranking of marketing media inducing customers to make purchases corresponds with the previous results. In the last six months, the clients were most inclined to buy goods when attracted by the clarity and graphic design of the website (over 16\%) and the presence in social media. The economic factor is not without significance - the third position with the score of $11 \%$ of responses was taken by the discounts offered when customers exceeded a specific value of the purchases. The worst in the ranking are brandmark and e-mailing (spam), running an internet forum and popup/under windows. Among other factors affecting purchases, the respondents indicated: discount codes/coupons available on the Internet.

The next element of the survey is the specification of a technical element - the tool which draws clients' attention to e-marketing to the greatest extent. Here the elements which are clearly visible on the screen, such as video - $27 \%$ of responses, or billboards $-23 \%$ of responses were decisively advantageous. Static and dynamic banners seem to be of lesser importance $20 \%$ of responses. The respondents pay the least attention to buttons or pop-up/under windows.

The last, most comprehensive section of the survey examined m-marketing functioning on mobile devices such as a smartphone or a tablet. The questions concerned people who simultaneously use traditional devices (PC/laptop) and modern mobile equipment (smartphone/tablet). Generally speaking, if we consider the respondents' approach to electronic marketing it is nearly in one-third of responses (31\%) negative. It appears that they prefer internet marketing on traditional hardware $(40 \%)$. Only $15 \%$ answers of respondents indicated the preference for marketing on modern devices, and $14 \%$ of survey participants' responses claim that they like both types of marketing.

Over $65 \%$ answers of respondents claim that marketing on traditional hardware and modern mobile devices is different, in $28 \%$ of responses - have no opinion on the subject, and only in $7 \%$ answers - think that such differences do not actually exist.

Among the factors which are most disliked by customers in the manifestations of mobile marketing, the frequent comments concern greater problems with closing them $(25 \%$ of responses) and their taking proportionally larger space on the screen $(24 \%)$. Nevertheless, the statements related to problems encountered when communicating with the device are almost at the same level $(23 \%)$. A half answers of the respondents still draws attention to the fact that displaying ads on mobile devices extends the time needed to roll the screens. Further positions are taken by the worse level of readability, connected with lower resolution, or excessive conciseness. Among other problems, the survey participants paid attention to the fact that older devices may be overloaded, and they tend to crash (see Fig.1).

Among the advantages of m-marketing, the respondents indicate the concise content ( $61 \%$ of responses), lower level of 


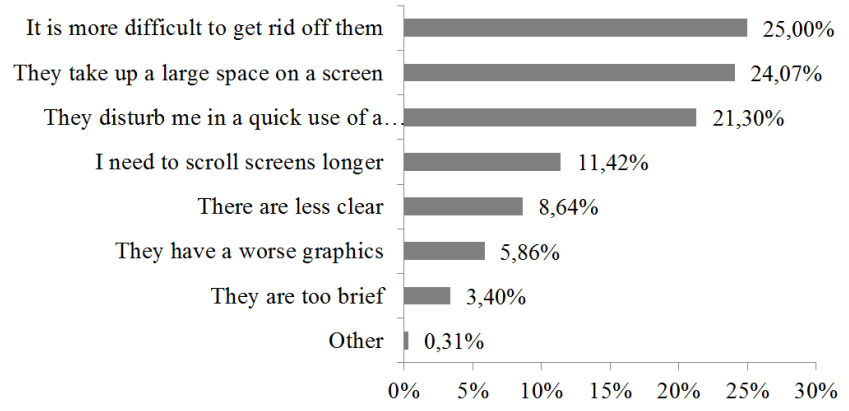

Fig. 1. Disadvantages of m-marketing in the respondents' opinions $(\% \%$ of responses); $\mathrm{n}=314$

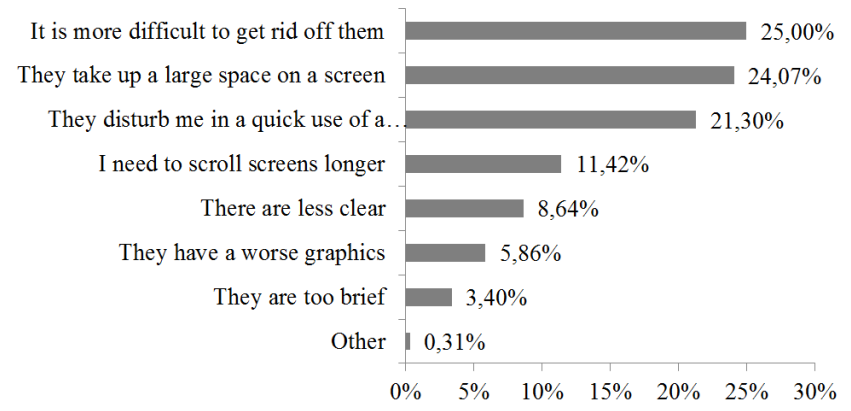

Fig. 2. The most important features of m-marketing (\%\% of responses) $\mathrm{n}=281$

intrusiveness of the tools $(25 \%)$ and the fact that, in general, they are easier to use $(14 \%)$. The responses show that the feature which is indicated by some users as a disadvantage (e.g. excessive conciseness), may be seen as an advantage by others (content which is limited to the minimum, i.e. brevity).

Detailed analysis of the above responses was conducted through the prism of the most important features of mobile marketing. In over $27 \%$ of responses it was indicated the facts that m-marketing is always available, and it guarantees the precise and fast way to reach out to the target group (18\%) are its most important features. The third position is taken by easy, dynamic and flexible interaction with the recipient $(17 \%$ of responses). The high level of effectiveness of this type of marketing raises serious doubts (see Fig. 2).

The next question concerned the types of m-marketing tools which are most frequently used by the respondents. The greatest number of users indicated the use of mobile applications (28\% of responses). The next positions are taken by SMS marketing - $26 \%$ of responses - and the use of geolocation and mobile navigation - 16\%. The lowest scores are assigned to designing mobile websites and the use of NFC technology and QR codes (about 9\% of responses). It appears that among the respondents few people used railway tickets (QR codes) or maps and guides (e.g. TatrzaÅĎski Park Narodowy). With regard to the question concerning the most visible forms of m-marketing the respondents pay the greatest attention to graphic advertising (73\% of responses), next to application ads $12 \%$ and text ads $10 \%$. In less than $5 \%$ answers of survey participants believe that the advertisements designed with the application of Google Web Designer technology prove to be most effective. Among m-marketing technologies operated on smartphones or tablets, the most efficient are graphic ads (43\% of responses), then graphic application ads and the application ads (about 17\% each). True View ads used to promote applications (about $1 \%$ of responses) and text ads (nearly 8\%) are seen as less effective. The last question concerned the form of mobile marketing, which the respondents used most frequently in the last six months. The most popular forms were mobile applications (e.g. product placement or display ads), which amounted to $28 \%$ of responses. SMS marketing took the next position. The use of other forms of m-marketing was 5-6 percentage points lower in the ranking. The least popular forms were NFC (Near Field Communication) technology or QR (Quick Response) codes - generally at the level of $9 \%$ of responses.

\section{CONCLUSIONS}

The conducted and presented studies point to the following conclusions:

- In the present study, all respondents of the survey were students, which was clearly indicated in the obtained findings. The higher the year of study, the less interest in completing the survey and its conclusions. It is probably caused by the greater effort required not only for the studies but also students' involvement with temporary or regular jobs (working students constitute more than $32 \%$ of the sample). On the other hand working students are very often used e-commers and have to do with emarketing.

- The frequency of the use of the Internet in the examined sample was high - over $95 \%$ of respondents replied that they use the Internet several times a day, and nearly $4 \%$ at least once a day; they were connecting to the Internet only via their smartphone (1/3 of the sample), the second most popular option was laptop. It is the generation that has learned how to use a mobile phone/mobile device relatively early in their life and later on switched to smartphones or tablets; the change has been fairly easy and natural for them. The transition was supported by a relatively low price, in comparison to a laptop, and a large number of free applications available on all three operational systems (Android, iOS, Windows) running on smartphones,

- In the examined group fewer than $50 \%$ of respondents do their shopping on the Internet several times a month, up to a few times a day, which indicates a specific shift of the role played by the Internet from the economic role to a more communicative-informative one, i.e. the change in the main function of mobile phones at present is no longer focusing on business relations (only $6 \%$ of the sample use the Internet at work). The core aspect of the mobile sphere starts to prevail over the desktop one. 
- At the same time, the Internet is generally perceived as a good and very good marketing medium - $85 \%$. As far as the high level of internet purchases is concerned, the users declare that purchases made outside the Internet may be seen as the outlet for marketing activity,

- Simultaneously respondents claim that internet marketing is better than a traditional one due to its: continuous availability, a quick way to broaden the knowledge about a product or service and a possibility to use comparison engines - including mobile tools,

- Information about goods and services continue to be gathered by means of browsers (almost $49 \%$ of responses); social media take the second position, and the role of blog entries is gaining in importance, other sources of information are marginalized,

- Among the elements which respondents pay the greatest attention to with regard to e-marketing, we may list general graphic design and an advertised product or service,

- Among the technical elements of marketing, the Internet users see the advantage of the elements which clearly stand out on the screen: video (short film), or billboards. Static or dynamic billboards seem to be slightly less important,

- Marketing tools are positively perceived mainly in social media, on corporate blogs, on websites and in online shops. It emerges that in social media and on websites they are seen as both eagerly viewed and irritating apparently to equal degree,

- A third of the "mobile generation" sees electronic marketing as a negative phenomenon, more people prefer to see it applied on traditional hardware rather than mobile devices,

- Over $65 \%$ of respondents believe that marketing via traditional equipment (PC, laptop) and modern devices (smartphone, tablet) are different,

- Among negative factors concerning m-marketing we experience greater problems with removing the ads from the screen, taking proportionally greater space and interfering in operating the device,

- Among the positive factors in m-marketing, the respondents mainly paid attention to concise contents, limited to a minimum, lower intrusiveness of the tool and the consequent greater comfort in using it,

- The most important feature of m-marketing is common availability, the guarantee of precise and fast access to the target group and easy, dynamic interaction with the recipient. However, there emerge certain doubts concerning the effectiveness of this form of marketing,
- The most popular type of m-marketing tool among the respondents were the ads available through mobile apps, SMS marketing as well as using geolocation and mobile navigation,

- The most noticeable forms of m-marketing are banners and much less (6 times less) noticeable app ads and text ads, and here lies, in the opinion of users, their greatest effectiveness,

- Most recently the respondents most frequently used the app-embedded ads (e.g. product placement and display) and SMS marketing.

The above conclusions constitute a proper basis for the continuation of the research as well as extending it to include the effects, consequences and results of using m-marketing in business activity.

\section{REFERENCES}

[1] Bernauer D., Mobile Internet - Grundlagen, Erfolgsfaktoren und Praxisbeispie-le. Vdm Verlag Dr. Müller.; 2008.

[2] Chmielarz W., Marketing w sieci, Chapter 3 in: Systemy elektronicznego biznesu, Difin, Warszawa, 2007, pp.139-168.

[3] Chmielarz W., Study of Smartphones Usage from the Customer's Point of View, Procedia Computer Science, Elsevier, Vol. 65, 2015, pp. 10851094, DOI: 10.1016/j.procs.2015.09.045.

[4] Gao T., Sultan F., Rohm A. J., Factors influencing Chinese youth consumers' acceptance of mobile marketing, Journal of Consume Marketing 27/7, 2010, pp. 574-583, DOI: 10.1108/07363761011086326.

[5] Hasan J., Analysis of E-marketing Strategies, Studia commercialia Bratislavensia, Volume 4; Number 14 (2/2011), 2011, pp. 201-208, DOI: 10.2478/v10151-011-0006-z.

[6] Hovancakova D., Mobile Marketing, Studia commercialia Bratislavensia, Volume 4; Number 14 (2/2011), 2011, pp. 211-225, DOI: 10.2478/v10151-011-0007-y.

[7] IAB,

http://iab.org.pl/badania-i-publikacje/ raport-iabpwc-adex-2015-q1, accessed 2016-04-11.

[8] InternetStandard, http://www.internetstandard.pl/news/401894/Reklama. online.dominuje.rynek.html(eklamaonlinedominujerynek), accessed 2016-04-10.

[9] Kiba-Janiak M., The Use of Mobile Phones by Customers in Retail Stores: a Case of Poland, Economics \& Sociology, Vol. 7, No 1, 2014, pp. 116-130, DOI: 10.14254/2071-789X.2014/7-1/11.

[10] Meng X., Developing Model of E-commerce E-marketing, Proceedings of the 2009 International Symposium on Information Processing (ISIP'09), Huangshan, P. R. China, August 21-23, 2009, pp. 225-228.

[11] Roach G., Consumer perceptions of mobile phone marketing a direct marketing innovation, Direct Marketing An International Journal Vol. 3 No. 2, 2009, pp. 124-138, DOI: 10.1108/17505930910964786.

[12] Salo J., Sinisalo J., Karjaluto H., Intentionally developed business network for mobile marketing: a case study from Finland, Journal of Business \& Industrial Marketing 23/7, 2008, pp.497-506, DOI: 10.1108/08858620810901257.

[13] Sun S., Innovation Mode and Strategy Research on Small and Mediumsized Enterprise E-marketing in Post Financing Crisis, Contemporary Logistics 04, 2011, p. 13.

[14] Świerczyńska-Kaczor U., e-Marketing przedsiębiorstwa w spoteczności wirtualnej, Difin, Warszawa, 2012.

[15] Wielki J., Relacje organizacji z jej klientami, Chapter 2.2.2., in: Modele wpływu przestrzeni elektronicznej na organizacje gospodarcze, Wydawnictwo Uniwersytetu Ekonomicznego we Wrocławiu, Wrocław, 2012, pp. 87-104 